\title{
Prediction Of Lamp Price Using Adaptive Neuro Fuzzy Inference System
}

\author{
Mohammad Ridwan ${ }^{1}$ \\ $\left\{\right.$ mridwan@unis.ac.id $\left.{ }^{1}\right\}$ \\ Islamic university Sheikh Yusuf, Maulana Yusuf Street No.10, Babakan, Kota Tangerang, Banten \\ Indonesia $^{1}$
}

\begin{abstract}
Precise Lamp predictions lead to the optimal allocation of resources, efficiency improvements, and increased company revenue. to forecast the price of building lights is a type of non-linear prediction. In this study, periodic data with time range of data from Jan-2009 to Dec-2015 used as prediction process parameter using ANFIS. The research method was started by mapping data into 4 input parameters and 1 output result, followed by training and testing 3 times with data classification period 1-19, 2-20, and 321. The result of the research Prediction of price using ANFIS model based on 63 data with 3 variant of light and input parameter that include number of membership function $=$ 2, membership function type Trapezium, error goal 0, and epoch Maximum 100 able to give value of $\mathrm{RMSE}=0.05$, MAPE $=5.62$, and produces predictive price according to actual data with percentage difference of 1,65x10-3.
\end{abstract}

Keywords: predicted price, ANFIS, fuzzy prediction, adaptive neuro network, fuzzy inference system.

\section{Introduction}

The level of accuracy of auction tender price of a building maintenance is closely related to the level of accuracy in determining the price of building maintenance materials, especially lamps. Determining the price of lights is a problem that is often faced by the planner bidding the auction price in building management (Building Management). Not only in Building Management institutions, even all agencies involved in the sale of goods / services for related goods also find the same problems in determining future budget planning. With so many phenomena and pricing issues happening, there are many researches done to solve the problem, but for price prediction research that focuses on the price of lights in the Building Price quote building section does not yet exist. Problems that occur in the institution of PT. Garuda Karya Mandiri is : (1) Frequent price forecasting errors during manufacture building lights auction bidding. (2) For the decision-making takes a long time, because the proposals predictions offered by several actors making up the price is not the same with each other. In other words, the lack of consistency in the proposed forecasting. As for the impact of an error in the price forecast among others: (1) Requires a long time in the decision-making price predictions proposals where near real-undoing. (2) Can lead to defeat in the competition offering price comparisons. (3) Difficulties in the planning of ongoing project work, because the costs to be incurred are not in accordance with the contract. (4) Stability will be disrupted, because the company's financial unit will be focused on the project at disburse additional fee

ICCSET 2018, October 25-26, Kudus, Indonesia

Copyright () 2018 EAI

DOI 10.4108/eai.24-10-2018.2280522 
to cover the cost of the underpayment and the exclusion of other projects. (5) Causes not optimal in the allocation of resources, improving efficiency, and increasing the company's revenue. From identification of problems exposed above, it may be obtained dimension of the problem is so vast. Furthermore, the problem which is the object of research is limited to the Prediction Model Analysis of Adaptive Neuro Fuzzy Inference System for forecasting the price of building lights at PT Garuda Karya Mandiri. Restrictions on this issue contains the concept of understanding as follows: (1) The data used is the lamp price history data from 2009 to 2015 a period of 4 months. (2) Using calculations Squere Root Mean Error (RMSE) and Mean Absolute Percentage Error (MAPE) to calculate the accuracy of the data.

The purpose of this study include: (1) To analyze the use of ANFIS model in predicting the price of building lights. (2) Obtain the best predictive models to forecast the price of building lights by using ANFIS.

\section{Literature Review}

There are several literature reviews Previous research that the researcher used as a reference and comparator in this research process is among others:

Time-series Extreme Event Forecasting with Neural Networks at Uber. This study produced an end-to-end neural network architecture for special event forecasting at Uber in the framework of the model's general forecasting applicability[1]. Comparison with current research : Previous research used the same basis as current research, namely artificial neural network techniques, but previous research did not explore the uncertainty of data and information, whereas when we talk about predictions there is some uncertain or gray information that we must thorough, while in the present research will also be examined about the uncertainty of information by using the fuzzy system method.

Modeling and Forecasting of Food Imports in Albania. This study produced the most appropriate model for forecasting the value of food imports by using Method with trend and seasonality, and seasonal ARIMA model[2]. Comparison with current research : Previous research uses a different method from current research, where the method used is a combination of hotl-winter and Arima Models that are still difficult to set, scale, and add exogenous variables, while for research that is now more easy by using a combination of fuzzy and time-series artificial neural networks.

A Real Time Patient Monitoring System based on Artificial Neural Fuzzy Inference System (ANFIS). the system to work as a smart healthcare system that decides the priority by itself based on the collected psychological parameters from the sensor nodes. Proposed model describes an e-healthcare monitoring system developed for realizing integration of ANFIS in healthcare monitoring systems[3]. Comparison with current research : Previous research used the same method as the current research, namely the ANFIS method with the background of different research objects. and there is also a very important difference, namely the previous research did not explain the testing method used in system testing while the current research uses RMSE and MAPE testing calculations as testing techniques.

it can be concluded that the difference of the three studies above with this study is the author analyzes Predicted Price Lights Building using Adaptive Neuro Fuzzy Inference System (ANFIS) using the parameters of historical data and Programming Matlab by testing using the Roots Mean Square Error (RMSE) and Mean Absolute Percentage error (MAPE). 


\section{Methods}

\subsection{Research Methods}

The focus of research put forward the model of Adaptive Neuro Fuzzy Inference System (ANFIS) for perpetrators maker Bid auction in PT Garuda Karya Mandiri (GKM) to create the results predicted light price is right and not hurt the company. ANFIS is a network model which Sugeno-type fuzzy system is combined with neural learning ability[4]. This research includes applied research. The results of the research can be directly applied to solve the problems faced.

In this study, will be made Prediction price using the model ANFIS, business analysis models using the method of functional analysis, techniques and results analysis to collect data using the method of interview expert person, while testing for quality prediction using the Root Mean Square Error (RMSE) and Mean Absolute Percentage Error (MAPE).

\subsection{Stages Research}

Research steps for designing ANFIS models are discussed[5]:

1. Specify the variables that are used for diagnosing problems.

Table 1. the variables used in this study, based on the parameters used by PT Garuda Karya Mandiri in the calculation of price predictions manually.

\begin{tabular}{cl}
\hline Function & \multicolumn{1}{c}{ Variable Name } \\
\hline Input & $\begin{array}{l}\text { History Data price building lights from January 2009 - December 2015 (3 } \\
\text { variants lights) } \\
\text { Output }\end{array}$ \\
Model Prediction best ANFIS \\
\hline
\end{tabular}

2. Specify the period of data used in the study. Here the authors use four month period (based on the activity data updates made by PT Garuda Karya Mandiri in order to predict the price).

3. Conducting research data normalization using the Min-Max normalization.

4. Map data normalization training with the details of 4 parameters as input and one as output. For rules as follows:

Table 2. Data Set Rule.

\begin{tabular}{cll}
\hline No & Parameter & \multicolumn{1}{c}{ Rules } \\
\hline 1 & $\begin{array}{l}\text { Only wear light } \\
\text { price history data }\end{array}$ & $\begin{array}{l}\text { parameter to 1,2,3, and 4 are four historical data from the previous } \\
\text { period output data, and parameters of the 5th as the output data is } \\
\text { known to do the training data. }\end{array}$ \\
\hline
\end{tabular}

\subsection{Sampling / Sample Selection Methods}

The sampling process is done by direct observation. The sample selection by 4 monthly periods from 2009 to 2015 using three variants. 


\subsection{Analysis method}

To make the learning process, the data will be divided into two parts, the data for the Training and Testing process. In this learning process, data to be processed is made in the form of normalization with the interval [0 1]. From the results of the learning process, then look for the value of performance statistics using RMSE and MAPE best. The Root Mean Squared Error Approach (RMSE) is a vital content in the analysis of different data homogeneous and heterogeneous data applications in science and engineering[6]. While the Mean Absolute Percent Error (MAPE) for the precision dimension[7]. Once you know the best data model, then the next stage is the prediction.

\section{Results And Discussion Research}

\subsection{Research result}

This study resulted in a price prediction modeling light by sampling the light pricing data from PTj Garuda Karya Mandiri.In this study, the data used by 63 with 3 variants of data stored in a light different .xlsx file, the data is placed on:

$$
\begin{array}{ll}
\text { - Sheet name } & \text { : Sheet1 } \\
\text { - Row Cell Data } & \text { N6-N26 }
\end{array}
$$

The data will be used and imported into Matlab for the Training and Testing ANFIS[8].

\subsubsection{Determination of Total Membership Function}

Membership function in this study are predictive variables of input data rates lights that have not known how the optimal amount to generate a predictive model that best price lamp. Total membership function will be tested using 2, 3, and 4 the number of membership function which then becomes a parameter comparisons to find the results of modeling the price of light using the number of membership functions which are able to provide the smallest RMSE and MAPE.

\subsubsection{Determination of Membership Function Type}

To get the value of membership is to approach functions. In this research, will be tested several types of membership functions, namely triangular membership functions (trimf), trapezoidal (trapmf), bells (gbellmf), and gaussian (gaussmf).

\subsubsection{Determination Methods of Optimization, Error Tolerance, and epochs}

Optimization method consists of two options, namely hybrid and propagation methods. One of the advantages of a hybrid method is convergent time relatively shorter than using backpropagation. Backpropagation network trained to strike a balance between the ability of the network to recognize the pattern of the network used for training as well as the network's 
ability to provide the correct response to the input pattern similar (but not equal) to the pattern that was used during the training.

Error Tolerance is the consequence arising from the program encountered an error. Epoch is a moment in time is used as a reference point. In this study, the method to be tested is a hybrid and propagation. Error tolerance used is 0, while its limited epoch in the 100th iteration.

\subsection{Discussion}

\subsubsection{Modeling Analysis and Application of Matlab ANFIS}

In this study executed several stages that are formulated with the rules of the theory of ANFIS modeling to achieve a model of ANFIS in predicting the price of building lights in accordance with the purpose of research. For details of the stages include:

\subsubsection{Load Data Research}

For data that will be formulated here in the form of Microsoft Excel files with names sheet "Sheet1" and the data is located on the cell N6: N26.

Table 3. Downlights C Max $15 \mathrm{~W}$.

\begin{tabular}{|c|c|c|c|}
\hline No & Month & Year & Price Lights \\
\hline \multirow[t]{3}{*}{1} & First 4 Months & 2009 & 36500 \\
\hline & Second 4 Months & & 32600 \\
\hline & Third 4 Months & & 30725 \\
\hline \multirow[t]{3}{*}{2} & First 4 Months & 2010 & 29575 \\
\hline & Second 4 Months & & 29225 \\
\hline & Third 4 Months & & 28850 \\
\hline \multirow[t]{3}{*}{3} & First 4 Months & 2011 & 28475 \\
\hline & Second 4 Months & & 27550 \\
\hline & Third 4 Months & & 28850 \\
\hline \multirow[t]{3}{*}{4} & First 4 Months & 2012 & 29475 \\
\hline & Second 4 Months & & 30375 \\
\hline & Third 4 Months & & 31025 \\
\hline \multirow[t]{3}{*}{5} & First 4 Months & 2013 & 31325 \\
\hline & Second 4 Months & & 32575 \\
\hline & Third 4 Months & & 37775 \\
\hline \multirow[t]{3}{*}{6} & First 4 Months & 2014 & 38325 \\
\hline & Second 4 Months & & 38275 \\
\hline & Third 4 Months & & 39800 \\
\hline \multirow[t]{3}{*}{7} & First 4 Months & 2015 & 42050 \\
\hline & Second 4 Months & & 43975 \\
\hline & Third 4 Months & & 45850 \\
\hline
\end{tabular}

The above is just one lamp data from January 2009 - December 2015. 


\subsubsection{Normalization Data Distribution}

Normalization is the way transformation of data in order to be a normal distribution. With the normalization process, will have a positive impact on the data to be processed and it will be easier to be analyzed by the system ANFIS. The study used the Min-Max normalization with reference to the minimum and maximum of the data. Excess Min-Max Normalization is a much simpler formula for processing system. There are 4 the number of input variables, namely price data building lights during 4 periods ( 1 period $=4$ months $)$ in advance to predict the period ahead. The actual data that is normalized beforehand with Eq 2:13.

\subsubsection{Data Mapping Training}

Next is the map data that is used by Training 4 input variables are $\mathrm{x} 1, \mathrm{x} 2$ and $\mathrm{x} 3$ and 1 output variable is $\mathrm{y}$. Training for mapping 1 starting from the period 1 st to 19 th period.

\subsubsection{Processing Generate FIS (Genfis)}

This process serves to evoke Fuzzy Inference System (FIS) to earlier should be set in advance the type of Membership Function and Total Membership Function. To do that, Matlab already provides a function that is able to control the process. The FIS has been raised with the input matriks 1x4, 1x1 matriks Output and 1x16 matriks rule.

\subsubsection{Processing ANFIS}

At this stage the ANFIS method can be used and is ready to run for download training data prepared beforehand. To run ANFIS process is necessary to know in advance the data that we had prepared beforehand and also determine, among other things:

a. The choice of method MF: hybrid or backpropagation

b. Error Tolerance: in this study the error value used were 0

c. Iteration epochs: up to 100

d. After determining the value of the method, error tolerance and epochs in the desired new ANFIS can be executed.

\subsubsection{Evaluate FIS (Evalfis)}

Once the data is grouped and form a matrix, the study's data ready to do the testing and training process to be handled by Matlab.

\subsubsection{Unnormalisasi Distribution Output}

After generates predictive value ANFIS with the type of normalization, to change shape according to the original data to be done in a way to reverse the process unnormalisasi normalization formula had become:

$$
\text { DataReal }=(\text { DataAnfis } *(\text { DataMin }- \text { DataMax })+\text { DataMin }
$$


The above formula is the result of a reversal of real data parameter of the formula MinMax normalization. With the above formula, the data will be returned to the original. With the data already diunnormalisasi, then the prediction model can already be tested to find the best ANFIS model formulation to predict the price of building lights.

\subsubsection{Simulation Model Using Matlab ANFIS}

In general, this is a modeling ANFIS ANFIS system design tailored to the needs of the simulation Predicted Price Lights using Matlab ANFIS-based programming. In designing this simulator includes a selection of the parameters needed in the Training and Testing ANFIS which includes Total Membership Function, Function Type Membership, Training Methods, Error Tolerance, epochs, and Training Option. Training ANFIS results can be used as reference to deduce how consistency Training ANFIS to these data. The following table shows the value of the consistency of the results Training ANFIS.

Table 4. Consistency Results Training ANFIS.

\begin{tabular}{clcrrrr}
\hline & & & Downlight & PLC & Essensial & Kon. \\
\hline First Training & RMSE & $:$ & 0.0000468 & 0.0000467 & 0.0000467 & $100 \%$ \\
& MAPE & $:$ & $0.0037 \%$ & $0.0037 \%$ & $0.0037 \%$ & $100 \%$ \\
& Iterasi & $:$ & 95 & 95 & 95 & $100 \%$ \\
Second & RMSE & $:$ & 0.0000540 & 0.0000540 & 0.0000540 & $100 \%$ \\
Training & MAPE & $:$ & $0.0039 \%$ & $0.0039 \%$ & $0.0039 \%$ & $100 \%$ \\
& Iterasi & $:$ & 100 & 100 & 100 & $100 \%$ \\
Thirth & RMSE & $:$ & 0.0000270 & 0.0000270 & 0.0000271 & $100 \%$ \\
Training & MAPE & $:$ & $0.0019 \%$ & $0.0019 \%$ & $0.0019 \%$ & $100 \%$ \\
& Iterasi & $:$ & 100 & 100 & 100 & $100 \%$ \\
\hline
\end{tabular}

The above table shows that the results Training and ANFIS have maximum consistency of these results also show that ANFIS is able to interpret the price predictions consistently lights.

\subsubsection{Testing Results / Simulation Testing ANFIS}

After training, the next step is testing or testing. Tests conducted on some parameters to test the reliability of the ANFIS method, ie by comparing an optimization method, the type of MF and MF number.

\subsubsection{Comparison of Methods of Optimization}

Testing in advance using Hybrid method with the results the following conclusions: 
Table 5. Results of Testing ANFIS Optimization Methods.

\begin{tabular}{lcc}
\hline Perbandingan Metode Optimasi & RMSE & MAPE \\
\hline Hybrid & 0,005 & 6,397 \\
Backpropagation & 0,05 & 6,51 \\
\hline
\end{tabular}

As seen in the table above, the value of RMSE and MAPE between Hybrid Method with Backpropagation have significant differences. Hybrid method RMSE and MAPE has a value smaller than Backpropagation method. So, Hybrid method will be used for further testing.

\subsubsection{Membership Type Comparison Function (MF)}

Further testing by comparing the types MF. The results of each Testing can be concluded as follows:

Table 6. Comparison MF mode.

\begin{tabular}{lllll}
\hline & Trimf & Trapmf & Gbellmf & Gaussmf \\
\hline RMSE & 0,057 & 0,050 & 0,132 & 0,10 \\
MAPE & 6,39 & 5,626 & 14,74 & 11,6 \\
\hline
\end{tabular}

From the table above obtained MF mode is best for this research that Trapmf, then Trapmf will be referred for further testing.

\subsubsection{Comparison of Total Membership Function (MF)}

In this study, the number of MF compared are 2, 3, and 4. Each of its Testing.

Table 7. Results of Testing Number MF.

\begin{tabular}{llll}
\hline & Jum MF = 2 & Jum MF = 3 & \multicolumn{1}{c}{ Jum MF = 4 } \\
\hline RMSE & 0,05 & 0,057 & 0,057 \\
MAPE & 5,62 & 6,44 & 6,44 \\
\hline
\end{tabular}

Number MF $=2$ is the smallest of the others. Thus, the number of MF corresponding to this research is 2 . From the results of the testing, the known value of the parameters that determine the reliability ANFIS models are as follows:

Optimization Method: Hybrid

Type MF : Trapmf

Number MF : : 2

\subsection{Interpretation Model}

Testing of the results of the above, it is known that the most appropriate technique ANFIS in predicting the price data of this building lights, among other methods using Hybrid Optimization, MF type using Trapmf, and the number of $\mathrm{MF}=2$. Further to the formula 
would have predicted the price of 5 th period up period to 21 with the third variant involves existing lights. The predicted results can be concluded that the model ANFIS using Hybrid Optimization methods, the number of MF 2 and MF types Trapezoid (Trapmf) successfully predict the price of building lights, with the average difference between the price in fact as follows:

Table 8. Percentage Difference Against Price Real Price Predictions.

\begin{tabular}{cccc}
\hline Percentage Difference & Lampu Downlight & Lampu PLC & Lampu Essential \\
\hline First Training & $0.00025 \%$ & $0.00000 \%$ & $0.00009 \%$ \\
Second Training & $0.01397 \%$ & $0.00000 \%$ & $0.00004 \%$ \\
Thirth Training & $0.00044 \%$ & $0.00000 \%$ & $0.00005 \%$ \\
\cline { 3 - 3 } & & $0.00165 \%$ \\
\hline
\end{tabular}

So with 3 results experimentation and testing of 3 items lamp using ANFIS research inni obtained an average price difference of a prediction of nayta price of $1.65 \times 10^{-3} \%$.

\section{Conclusions}

In the modeling study predicted the price of building lights by applying Adaptive Neuro Fuzzy Inference System, a number of conclusions as follows:

1) Consistency of results Training ANFIS model predictions on prices that have been simulated lamps generate value RMSE and MAPE are best with a value of $100 \%$ consistency.

2) The research result Model ANFIS using input parameters number of membership function as much as 2 types of membership functions Trapezoid (Trapmf), error goal of 0 , and the epoch maximum of 100 is able to give the test results Root Mean Square Error (RMSE) and Mean Absolute Percentage Error (MAPE) most and managed to create the best predictive results that correspond to the actual data with the average value of the price difference of $1.65 \times 10^{-3} \%$.

\section{References}

[1] N. Laptev, J. Yosinski, L. E. Li, and S. Smyl, "Time-series Extreme Event Forecasting with Neural Networks at Uber," ICML 2017 Time Ser. Work., p. 8, 2017.

[2] A. B. Spaho and E. Sala, "Modeling and Forecasting of Food Imports in Albania," vol. 15, no. 4, pp. 200-205, 2016.

[3] K. Singh, D. Sharma, and S. Aggarwal, "A Real Time Patient Monitoring System based on Artificial Neural Fuzzy Inference System (ANFIS),” Int. J. Comput. Appl., vol. 146, no. 15, pp. 975 8887, 2016.

[4] B. Haznedar and A. Kalinli, "Training ANFIS Using Genetic Algorithm for Dynamic Systems Identification,” Int. J. Intell. Syst. Appl. Eng., vol. 4, no. Special Issue, pp. 44-47, 2016. 
[5] L. Wei, "A Hybrid Model Based on ANFIS and Empirical Mode Decomposition for Stock Forecasting," vol. 3, no. 3, pp. 356-359, 2015.

[6] S. K. K. Babu, M. Sunitha, and M. V Ramanaiah, "Mathematical Modelling of RMSE Approach on Agricultural Financial Data Sets," vol. 5, no. 6, pp. 942-947, 2017.

[7] A. David, "On the Relationship among Values of the Same Summary Measure of Error when it is used across Multiple Characteristics at the Same Point in Time: An Examination of MALPE and MAPE 1,”2015.

[8] R. Prasad, "Evaluation of Interval Type-2 Fuzzy Membership Function \& Robust Design of Power System Stabilizer for SMIB Power System Evaluation of interval type-2 fuzzy members hip function \& robust design of powe r system stabilizer for SMIB power system," no. May, 2014. 